\title{
The bZIP transcription factor PERIANTHIA: a multifunctional hub for meristem control
}

\author{
Annette T. Maier ${ }^{1,2}$, Sandra Stehling-Sun ${ }^{2+}$, Sarah-Lena Offenburger ${ }^{2}$ and Jan U. Lohmann ${ }^{1}$ * \\ 1 Department of Stem Cell Biology, Centre for Organismal Studies Heidelberg, Heidelberg University, Heidelberg, Germany \\ ${ }^{2}$ Max Planck Institute for Developmental Biology, Tübingen, Germany
}

Edited by:

Andreas P. M. Weber, University of Duesseldorf, Germany

Reviewed by:

Yvonne Stahl, Heinrich-Heine

University, Germany

Kay Schneitz, Technische Universität

München, Germany

*Correspondence:

Jan U. Lohmann, Department of

Stem Cell Biology, Centre for

Organismal Studies, University of

Heidelberg, Im Neuenheimer Feld

230, D-69120 Heidelberg, Germany.

e-mail: jlohmann@meristemania.org

${ }^{+}$Present address:

Sandra Stehling-Sun, University of Washington, Seattle, WA, USA
As sessile organisms, plants are exposed to extreme variations in environmental conditions over the course of their lives. Since plants grow and initiate new organs continuously, they have to modulate the underlying developmental program accordingly to cope with this challenge. At the heart of this extraordinary developmental plasticity are pluripotent stem cells, which are maintained during the entire life-cycle of the plant and that are embedded within dynamic stem cell niches. While the complex regulatory principles of plant stem cell control under artificial constant growth conditions begin to emerge, virtually nothing is known about how this circuit adapts to variations in the environment. In addition to the local feedback system constituted by the homeodomain transcription factor WUSCHEL (WUS) and the CLAVATA signaling cascade in the center of the shoot apical meristem (SAM), the bZIP transcription factor PERIANTHIA (PAN) not only has a broader expression domain in SAM and flowers, but also carries out more diverse functions in meristem maintenance: pan mutants show alterations in environmental response, shoot meristem size, floral organ number, and exhibit severe defects in termination of floral stem cells in an environment dependent fashion. Genetic and genomic analyses indicate that PAN interacts with a plethora of developmental pathways including light, plant hormone, and meristem control systems, suggesting that PAN is as an important regulatory node in the network of plant stem cell control.

Keywords: Arabidopsis, meristem regulation, stem cells, auxin, cytokinin, PERIANTHIA, type-A ARR, SHOOTMERISTEMLESS

\section{INTRODUCTION}

In contrast to most animals, plants continue to form new organs throughout their lives. This remarkable capacity is dependent on the continuous presence of undifferentiated and self-renewing stem cells over long periods of time. These stem cells reside at the growing points of a plant, the tips of roots and shoots, and are embedded into specialized structures called meristems (Barton, 2010).

Several genes affecting meristem and stem cell function have been identified by mutant screens in Arabidopsis thaliana. Most notably WUSCHEL (WUS) and SHOOTMERISTEMLESS (STM) are required for the maintenance of the shoot meristem (Barton and Poethig, 1993; Laux et al., 1996; Long et al., 1996; Mayer et al., 1998). Their inactivation causes premature differentiation and the eventual exhaustion of the stem cell pool, leading to the termination of the shoot meristem. Another group of genes, the CLAVATA $(C L V)$ genes, have an opposite effect on meristems and if defective, shoot meristems overproliferate and expand inappropriately (Clark et al., 1993, 1995; Kayes and Clark, 1998).

With the exception of $C L V 2$, all genes mentioned above are expressed in small domains in the shoot apical meristem (SAM). Elegant genetic studies have shown that WUS and CLV3 are connected by a negative feedback loop to control the size of the stem cell pool. WUS, which is expressed in the organizing center, induces the expression of $C L V 3$ in the overlying true stem cells, which in turn signals back to the organizing center to keep WUS expression in check (Brand et al., 2000; Schoof et al., 2000). In addition to these local regulatory interactions, meristem function is affected by global hormone signaling pathways, including auxin and cytokinin circuitries. While STM mediates cytokinin biosynthesis (Jasinski et al., 2005; Yanai et al., 2005) to allow cell proliferation in the meristem, its expression is repressed by auxin (Furutani et al., 2004), which in turn allows organ initiation on the flanks of the SAM. In contrast, WUS does not interfere with cytokinin biosynthesis, but directly regulates Atype ARABIDOPSIS RESPONSE REGULATORS (ARRs; Leibfried et al., 2005; Busch et al., 2010) that act in the negative feedback regulation of cytokinin response (To et al., 2004). This feedback system of cytokinin signal transduction is also connected to auxin signaling and $A R R 7$ and $A R R 15$ are directly repressed by the AUXIN RESPONSE FACTOR5/MONOPTEROS transcription factor (Zhao et al., 2010). A-type ARRs execute important meristematic functions (Leibfried et al., 2005; Buechel et al., 2010; Zhao et al., 2010) by so far undiscovered mechanisms (Leibfried et al., 2005; Zhao et al., 2010).

Cells that leave the shoot meristem during the initial, vegetative phase of the life-cycle give rise to leaves and meristems of axillary shoots. After the transition to the reproductive phase, meristems that newly arise at the flanks of the SAM will develop into flowers instead. This is due to the redundant activity of meristem identity 
genes such as LEAFY (LFY) and APETALA1 (AP1). In contrast to the shoot apex, which is indeterminate, flowers are determinate and stem cell activity ceases after a fixed number of organs have been formed. In plants that lack LFY activity, flowers are converted into partially indeterminate shoot-like structures (Weigel et al., 1992).

One set of genes that is directly controlled by the LFY transcription factor includes homeotic genes that specify the fate of the different floral organs (Parcy et al., 1998; Busch et al., 1999). We have previously shown that LFY acts together with WUS, which also encodes a transcription factor, to contribute to the transcriptional activation of the homeotic gene AGAMOUS $(A G)$ in the center of young flowers. AG in turn, not only specifies the fate of the floral reproductive organs, but also terminates stem cell maintenance by negative feedback on WUS expression (Lohmann et al., 2001). The bZIP transcription factor PERIANTHIA (PAN) is expressed in the SAM, as well as in developing flowers, where it overlaps with STM, WUS, the CLV transcripts, and $A G$, respectively (Chuang et al., 1999). Loss-of PAN function leads to an increase in the number of perianth organs, the sepals and petals, while on a gross morphological level the SAM seems unaffected (Running and Meyerowitz, 1996). In flowers, PAN genetically interacts with $\mathrm{ABC}$ homeotic genes, however these interactions appear mostly additive (Running and Meyerowitz, 1996). PAN protein expression was shown to be independent of the meristematic regulators $C L V 1$ and $C L V 3$ as well as of floral meristem identity genes, such as $L F Y$ or $A P 1$, demonstrating that $P A N$ also acts in parallel to these factors (Chuang et al., 1999). It has been shown that PAN interacts with the NPR1-like proteins BLADE ON PETIOLE 1 (BOP1) and BOP2 in yeast and that bop mutants share some of pan mutant features (Hepworth et al., 2005). However, their expression domains only overlap marginally, suggesting that PAN primarily acts together with other co-factors. It was shown that PAN plays important roles in the activation of $A G$ (Das et al., 2009; Maier et al., 2009), which are strikingly modified in various day-length settings. While PAN brings about the termination of floral stem cell fate by the direct transcriptional activation of $A G$, its function in the SAM, where it is also strongly and specifically expressed, remains poorly understood.

\section{RESULTS AND DISCUSSION}

Since we had noted before that the floral functions of PAN are strongly dependent on the environment (Maier et al., 2009), we carefully analyzed vegetative phenotypes of wild-type Columbia and pan mutant plants under various growth conditions and found that day-length had a substantial impact on the penetrance of pan related defects. In contrast to the reproductive phase, where pan mutants showed the most dramatic aberrations under short-day conditions, pan plants at the early vegetative stage were largely undistinguishable from wild-type in short days (SD; Figures 1A,D). Conversely, pan mutants exhibited pleiotropic phenotypes when exposed to long days (LD), including elongated petioles, curled leaves, and a twisted rosette (Figures 1B,E). Under continuous light (CL), Col and pan phenotypes were less distinct, but pan plants continued to show more extreme leaf-curling and rosette twisting. In addition to the morphological traits, we observed that pan mutants flowered slightly early and on average formed 1.5 or 2.5 rosette leaves less than wild-type under LD or CL, respectively (Figure 3A; $n=50$ ). Furthermore, we realized that pan mutants are extremely sensitive to variations in diverse environmental conditions, including water and nutrient availability, as well as biotic and abiotic stress (data not shown). Taken

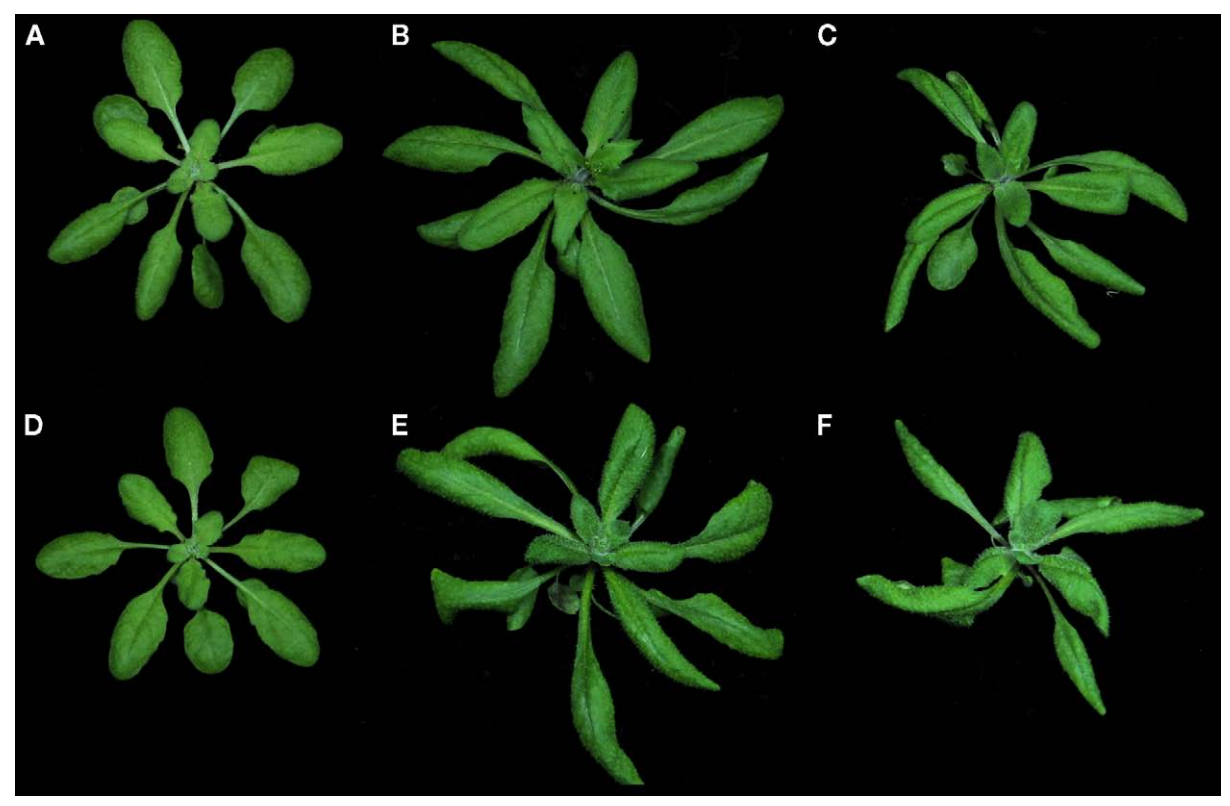

FIGURE 1 |Vegetative phenotypes in response to environmental conditions (A-F). Phenotype of wild-type (A-C) and pan mutant (D-F) plants grown under short-day [SD (A,D)], long-day [LD (B,E)], and continuous light [CL (C,F)] conditions for 21 days. Note leaf-curling, elongated petioles and twisted leaf rosettes under LD and CL conditions. 


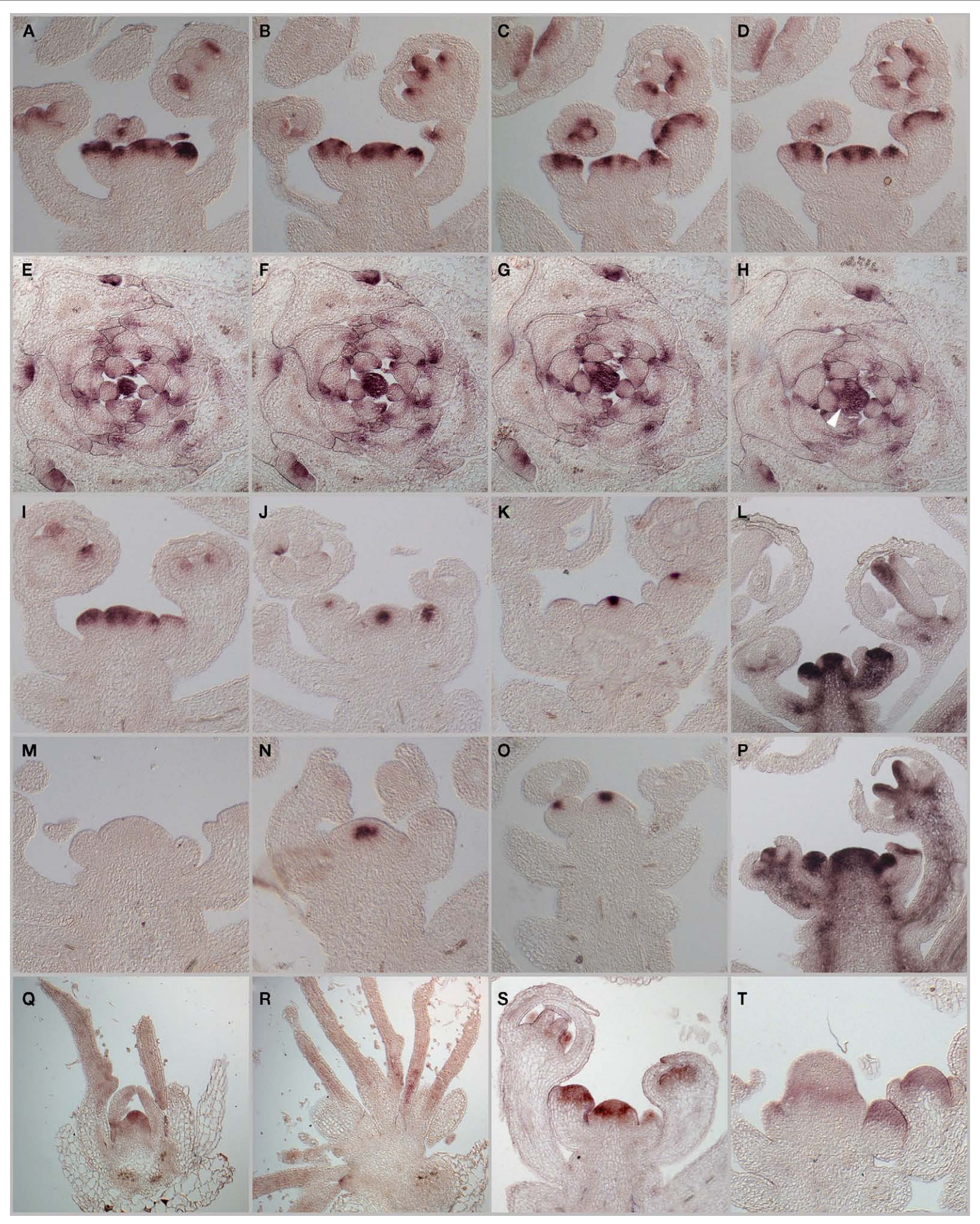

\section{FIGURE 2 | mRNA-expression patterns of PAN and SAM}

regulators WUS, CLV3, STM. In situ hybridizations were used

to analyze PAN mRNA-expression patterns. (A-D) Serial longitudinal sections of wild-type inflorescence apices after 25 days of growth LD. (E-L) Serial cross sections of a vegetative apex grown in 23 days in SD. PAN mRNA shows varying expression with a local maximum in a ring domain around the central zone. PAN expression is reduced in newly arising organ primordia [P3-P0, see arrowhead in (H)]. Expression patterns of PAN, WUS, CLV3, and STM in inflorescence apices of wild-type (I-L) and pan mutant plants (M-P). PAN

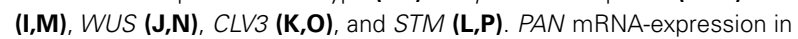
vegetative tissues of wild-type (Q) and wus mutants (R). PAN expression in wild-type (S) and ring-like expression in enlarged floral tissues on $c / v 3$ mutant (T). 

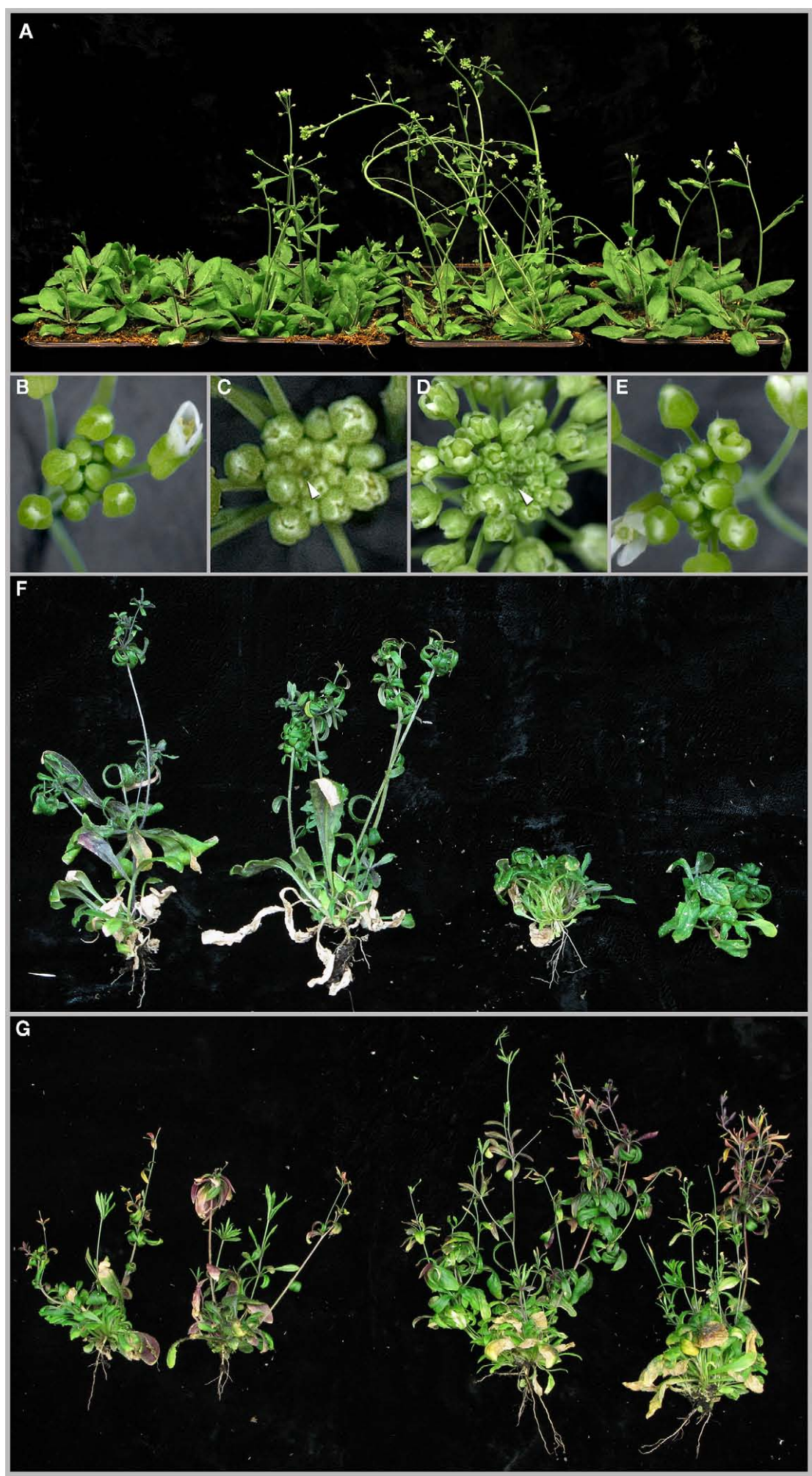

FIGURE 3 | Genetic interactions of PAN with CLV3, WUS, and STM.

(A) From left to right the following genotypes are shown: wild-type, clv3, pan clv3, and pan. Top views of inflorescence apices of wild-type (B), clv3 (C), pan clv3 (D), and pan (E) inflorescences. (F) Two wus mutant plants (left) are shown in comparison to two pan wus double mutants (right). Note the inhibition of shoot outgrowth in the double mutant. At later developmental stages a reduced number of shoots grows at a slow rate. (G) Two stm mutants (left) and two pan stm double mutant plants (right). Note the elevated number of shoots and branches, as well as floral buds in the pan stm double mutant. 
Table 1 | Genes with significantly increased expression in inflorescence apices of pan mutants (Rank Products FDR 0.05).

\begin{tabular}{|c|c|c|c|}
\hline $\begin{array}{l}\text { Array } \\
\text { element }\end{array}$ & $\begin{array}{l}\text { Fold } \\
\text { change }\end{array}$ & $\begin{array}{l}\text { Locus } \\
\text { identifier }\end{array}$ & Annotation \\
\hline 261059_at & 2.90 & AT1G01250 & AP2 domain-containing transcription factor putative \\
\hline 261564_at & 1.78 & AT1G01720 & ATAF1 (Arabidopsis NAC domain-containing protein 2); transcription factor \\
\hline 264606_at & 1.90 & AT1G04660 & Glycine-rich protein \\
\hline 261077_at & 3.17 & AT1G07430 & Protein phosphatase $2 \mathrm{C}$ putative/PP2C putative \\
\hline 261068_at & 2.01 & AT1G07450 & Tropinone reductase putative/tropine dehydrogenase putative \\
\hline 261485_at & 1.90 & AT1G14360 & $\begin{array}{l}\text { ATUTR3/UTR3 (UDP-GALACTOSE TRANSPORTER 3); pyrimidine nucleotide sugar transmembrane trans- } \\
\text { porter }\end{array}$ \\
\hline 261037_at & 2.51 & AT1G17420 & $\begin{array}{l}\text { LOX3 (Lipoxygenase 3); iron ion binding/lipoxygenase/metal ion binding/oxidoreductase acting on single } \\
\text { donors with incorporation of molecular oxygen incorporation of two atoms of oxygen }\end{array}$ \\
\hline 261222_at & 2.13 & AT1G20120 & Family II extracellular lipase putative \\
\hline 261224_at & 2.38 & AT1G20160 & ATSBT5.2; subtilase \\
\hline 264211_at & 3.48 & AT1G22770 & GI (GIGANTEA); binding \\
\hline 265186_at & 2.35 & AT1G23560 & $\begin{array}{l}\text { Similar to unknown protein [Arabidopsis thaliana] (TAIR:AT1G70480.2); similar to unknown pro- } \\
\text { tein [Arabidopsis thaliana] (TAIR:AT1G70480.1); similar to unnamed protein product [Vitis vinifera] } \\
\text { (GB:CAO66084.1); contains InterPro domain Protein of unknown function DUF220 (InterPro:IPR003863) }\end{array}$ \\
\hline 265002_at & 3.00 & AT1G24400 & LHT2 (LYSINE HISTIDINE TRANSPORTER 2); amino acid transmembrane transporter \\
\hline 261650_at & 1.80 & AT1G27770 & ACA1 (autoinhibited Ca2+-ATPase 1); calcium-transporting ATPase/calmodulin binding \\
\hline 259607_at & 1.96 & AT1G27940 & PGP13 (P-GLYCOPROTEIN 13); ATPase coupled to transmembrane movement of substances \\
\hline 262736_at & 2.12 & AT1G28570 & GDSL-motif lipase putative \\
\hline 245246_at & 2.58 & AT1G44224 & Encodes a ECA1 gametogenesis related family protein \\
\hline 262436_at & 1.73 & AT1G47610 & Transducin family protein/WD-40 repeat family protein \\
\hline 260727_at & 2.34 & AT1G48100 & Glycoside hydrolase family 28 protein/polygalacturonase (pectinase) family protein \\
\hline 256145_at & 1.73 & AT1G48750 & Protease inhibitor/seed storage/lipid transfer protein (LTP) family protein \\
\hline 256181_at & 2.04 & AT1G51820 & Leucine-rich repeat protein kinase putative \\
\hline 262128_at & 2.12 & AT1G52690 & Late embryogenesis abundant protein putative/LEA protein putative \\
\hline 263174_at & 1.88 & AT1G54040 & ESP (EPITHIOSPECIFIER PROTEIN) \\
\hline 263158_at & 3.99 & AT1G54160 & CCAAT-binding transcription factor (CBF-B/NF-YA) family protein \\
\hline 265075_at & 2.54 & AT1G55450 & Embryo-abundant protein-related \\
\hline 264882_at & 2.00 & AT1G61110 & ANAC025 (Arabidopsis NAC domain-containing protein 25); transcription factor \\
\hline 264400_at & 1.94 & AT1G61800 & $\begin{array}{l}\text { GPT2 (glucose-6-phosphate/phosphate translocator 2); antiporter/glucose-6-phosphate transmembrane } \\
\text { transporter }\end{array}$ \\
\hline 265122_at & 1.93 & AT1G62540 & Flavin-containing monooxygenase family protein/FMO family protein \\
\hline 265109_s_at & 1.78 & $\begin{array}{l}\text { AT1G63360; } \\
\text { AT1G62630 }\end{array}$ & $\begin{array}{l}\text { [AT1G63360. disease resistance protein (CC-NBS-LRR class). putative]; [AT1G62630. disease resistance } \\
\text { protein (CC-NBS-LRR class). putative] }\end{array}$ \\
\hline 264636_at & 2.57 & AT1G65490 & Similar to unknown protein [Arabidopsis thaliana](TAIR:AT1G65486.1) \\
\hline 259753_at & 1.77 & AT1G71050 & Heavy-metal-associated domain-containing protein/copper chaperone (CCH)-related \\
\hline
\end{tabular}


Table 1 | Continued

\begin{tabular}{|c|c|c|c|}
\hline $\begin{array}{l}\text { Array } \\
\text { element }\end{array}$ & $\begin{array}{l}\text { Fold } \\
\text { change }\end{array}$ & $\begin{array}{l}\text { Locus } \\
\text { identifier }\end{array}$ & Annotation \\
\hline 256335_at & 2.32 & AT1G72110 & $\begin{array}{l}\text { Similar to unknown protein [Arabidopsis thaliana](TAIR:AT2G38995.1); similar to unnamed protein prod- } \\
\text { uct [Vitis vinifera] (GB:CAO48523.1); contains InterPro domain Protein of unknown function UPF0089 } \\
\text { (InterPro:IPR004255); contains InterPro domain Protein of unknown function DUF1298 (InterPro:IPR009721) }\end{array}$ \\
\hline 259852_at & 2.20 & AT1G72280 & $\begin{array}{l}\text { AERO1 (ARABIDOPSIS ENDOPLASMIC RETICULUM OXIDOREDUCTINS 1); FAD binding/electron car- } \\
\text { rier/oxidoreductase acting on sulfur group of donors disulfide as acceptor/protein binding }\end{array}$ \\
\hline 262374_s_at & 2.02 & $\begin{array}{l}\text { AT1G72910; } \\
\text { AT1G72930 }\end{array}$ & $\begin{array}{l}\text { [AT1G72910. disease resistance protein (TIR-NBS class). putative]; [AT1G72930. TIR (TOLL/INTERLEUKIN-1 } \\
\text { RECEPTOR-LIKE); transmembrane receptor] }\end{array}$ \\
\hline 245734_at & 2.26 & AT1G73480 & Hydrolase alpha/beta fold family protein \\
\hline 260046_at & 1.81 & AT1G73805 & Calmodulin binding \\
\hline 260228_at & 3.97 & AT1G74540 & CYP98A8 (cytochrome P450. family 98. subfamily A. polypeptide 8); oxygen binding \\
\hline 262697_at & 2.09 & AT1G75940 & ATA27 (Arabidopsis thaliana anther 27); hydrolase hydrolyzing O-glycosyl compounds \\
\hline 261749_at & 1.71 & AT1G76180 & ERD14 (EARLY RESPONSE TO DEHYDRATION 14) \\
\hline 264482_at & 2.38 & AT1G77210 & Sugar transporter putative \\
\hline 259705_at & 2.85 & AT1G77450 & ANAC032 (Arabidopsis NAC domain-containing protein 32); transcription factor \\
\hline 262050_at & 4.05 & AT1G80130 & Binding \\
\hline 267483_at & 1.98 & AT2G02810 & $\begin{array}{l}\text { ATUTR1/UTR1 (UDP-GALACTOSE TRANSPORTER 1); UDP-galactose transmembrane transporter/UDP- } \\
\text { glucose transmembrane transporter/pyrimidine nucleotide sugar transmembrane transporter }\end{array}$ \\
\hline 266770_at & 1.82 & AT2G03090 & ATEXPA15 (ARABIDOPSIS THALIANA EXPANSIN A15) \\
\hline 263363_at & 3.78 & AT2G03850 & Late embryogenesis abundant domain-containing protein/LEA domain-containing protein \\
\hline 263073_at & 1.95 & AT2G17500 & Auxin efflux carrier family protein \\
\hline 265984_at & 1.91 & AT2G24210 & TPS10 (TERPENE SYNTHASE 10); myrcene/(E)-beta-ocimene synthase \\
\hline 265898_at & 1.90 & AT2G25690 & Senescence-associated protein-related \\
\hline 245035_at & 1.96 & AT2G26400 & $\begin{array}{l}\text { ARD/ATARD3 (ACIREDUCTONE DIOXYGENASE); acireductone dioxygenase [iron(II)-requiring]/heteroglycan } \\
\text { binding/metal ion binding }\end{array}$ \\
\hline 267595_at & 2.30 & AT2G32990 & $\begin{array}{l}\text { ATGH9B8 (ARABIDOPSIS THALIANA GLYCOSYL HYDROLASE 9B8); hydrolase hydrolyzing O-glycosyl } \\
\text { compounds }\end{array}$ \\
\hline 255795_at & 1.74 & AT2G33380 & RD20 (RESPONSIVE TO DESSICATION 20); calcium ion binding \\
\hline 267429_at & 2.81 & AT2G34850 & MEE25 (maternal effect embryo arrest 25); catalytic \\
\hline 266086_at & 1.96 & AT2G38060 & Transporter-related \\
\hline 257382_at & 1.80 & AT2G40750 & WRKY54 (WRKY DNA-binding protein 54); transcription factor \\
\hline 267083_at & 1.73 & AT2G41100 & $\mathrm{TCH} 3(\mathrm{TOUCH} 3)$ \\
\hline 266423_at & 1.75 & AT2G41340 & Eukaryotic rpb5 RNA polymerase subunit family protein \\
\hline 266555_at & 1.90 & AT2G46270 & GBF3 (G-BOX BINDING FACTOR 3); transcription factor \\
\hline 266326_at & 2.04 & AT2G46650 & B5 \#1 (cytochrome b5 family protein \#1); heme binding/transition metal ion binding \\
\hline 266327_at & 2.06 & AT2G46680 & ATHB-7 (ARABIDOPSIS THALIANA HOMEOBOX 7); transcription factor \\
\hline 263320_at & 1.80 & AT2G47180 & ATGOLS1 (ARABIDOPSIS THALIANA GALACTINOL SYNTHASE 1); transferase transferring hexosyl groups \\
\hline 259352_at & 9.07 & AT3G05170 & Phosphoglycerate/bisphosphoglycerate mutase family protein \\
\hline 258894_at & 1.98 & AT3G05650 & Disease resistance family protein \\
\hline
\end{tabular}


Table 1 | Continued

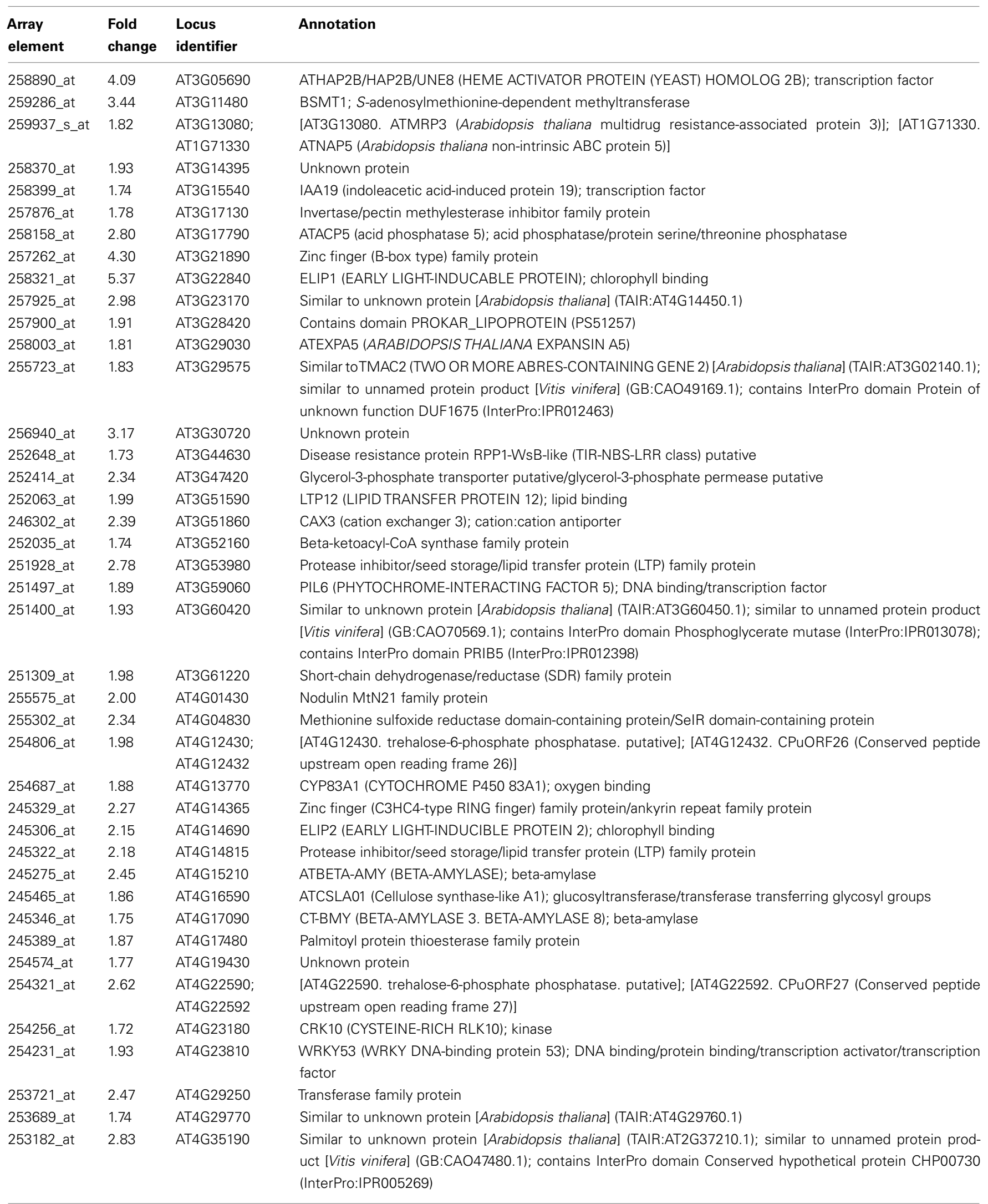


Table 1 | Continued

\begin{tabular}{|c|c|c|c|}
\hline $\begin{array}{l}\text { Array } \\
\text { element }\end{array}$ & $\begin{array}{l}\text { Fold } \\
\text { change }\end{array}$ & $\begin{array}{l}\text { Locus } \\
\text { identifier }\end{array}$ & Annotation \\
\hline 252870_at & 1.97 & AT4G39940 & AKN2 (APS-KINASE 2); ATP binding/kinase/transferase transferring phosphorus-containing groups \\
\hline 251065_at & 1.78 & AT5G01870 & Lipid transfer protein putative \\
\hline 250688_at & 6.33 & AT5G06510 & CCAAT-binding transcription factor (CBF-B/NF-YA) family protein \\
\hline 250665_at & 2.38 & AT5G06980 & Similar to unknown protein [Arabidopsis thaliana] (TAIR:AT3G12320.1) \\
\hline 250637_at & 1.76 & AT5G07530 & GRP17 (Glycine-rich protein 17) \\
\hline 250610_at & 3.03 & AT5G07550 & GRP19 (Glycine-rich protein 19) \\
\hline 250639_at & 2.73 & AT5G07560 & GRP20 (Glycine-rich protein 20); nutrient reservoir \\
\hline 250435_at & 2.18 & AT5G10380 & Zinc finger (C3HC4-type RING finger) family protein \\
\hline 250304_at & 2.14 & AT5G12110 & Elongation factor 1B alpha-subunit 1 (eEF1Balpha1) \\
\hline 246418_at & 2.02 & AT5G16960 & NADP-dependent oxidoreductase putative \\
\hline 250083_at & 1.79 & AT5G17220 & ATGSTF12 (GLUTATHIONE S-TRANSFERASE 26); glutathione transferase \\
\hline 246437_at & 1.95 & AT5G17540 & Transferase family protein \\
\hline 249918_at & 2.34 & AT5G19240 & $\begin{array}{l}\text { Identical to uncharacterized GPI-anchored protein At5g19240 precursor [Arabidopsis thaliana] } \\
\text { (GB:Q84VZ5;GB:Q8H7A4); similar to unknown protein [Arabidopsis thaliana] (TAIR:AT5G19230.1); similar to } \\
\text { unknown [Populus trichocarpa] (GB:ABK94712.1) }\end{array}$ \\
\hline 246071_at & 1.77 & AT5G20150 & SPX (SYG1/Pho81/XPR1) domain-containing protein \\
\hline 246099_at & 3.70 & AT5G20230 & ATBCB (ARABIDOPSIS BLUE-COPPER-BINDING PROTEIN); copper ion binding \\
\hline 249941_at & 1.81 & AT5G22270 & $\begin{array}{l}\text { Similar to unknown protein [Arabidopsis thaliana] (TAIR:AT5G06270.1); similar to unnamed protein product } \\
\text { [Vitis vinifera] (GB:CA015841.1); similar to hypothetical protein [Vitis vinifera] (GB:CAN79170.1) }\end{array}$ \\
\hline 249754_at & 2.05 & AT5G24530 & Oxidoreductase 2OG-Fe(II) oxygenase family protein \\
\hline 246967_at & 1.95 & AT5G24860 & FPF1 (FLOWERING PROMOTING FACTOR 1) \\
\hline 249112_at & 2.35 & AT5G43780 & APS4 \\
\hline 248716_at & 2.05 & AT5G48210 & Similar to unknown protein [Arabidopsis thaliana] (TAIR:AT3G42565.1) \\
\hline 248638_at & 2.85 & AT5G49070 & Beta-ketoacyl-CoA synthase family protein \\
\hline 248375_at & 1.85 & AT5G51710 & KEA5 (K+ efflux antiporter 5); potassium:hydrogen antiporter \\
\hline 248327_at & 2.44 & AT5G52750 & Heavy-metal-associated domain-containing protein \\
\hline 248160_at & 2.74 & AT5G54470 & Zinc finger (B-box type) family protein \\
\hline 248104_at & 1.81 & AT5G55250 & IAMT1 (IAA CARBOXYLMETHYLTRANSFERASE 1); S-adenosylmethionine-dependent methyltransferase \\
\hline 248011_at & 2.25 & AT5G56300 & GAMT2; S-adenosylmethionine-dependent methyltransferase/gibberellin carboxyl-O-methyltransferase \\
\hline 247718_at & 3.69 & AT5G59310 & LTP4 (LIPID TRANSFER PROTEIN 4); lipid binding \\
\hline 247717_at & 3.09 & AT5G59320 & LTP3 (LIPID TRANSFER PROTEIN 3); lipid binding \\
\hline 247657_at & 1.96 & AT5G59845 & Gibberellin-regulated family protein \\
\hline 247639_s_at & 1.92 & $\begin{array}{l}\text { AT5G60500; } \\
\text { AT5G60510 }\end{array}$ & $\begin{array}{l}\text { (AT5G60500. undecaprenyl pyrophosphate synthetase family protein/UPP synthetase family protein); } \\
\text { (AT5G60510. undecaprenyl pyrophosphate synthetase family protein/UPP synthetase family protein) }\end{array}$ \\
\hline 247426_at & 2.12 & AT5G62570 & Calmodulin-binding protein \\
\hline 247447_at & 1.98 & AT5G62730 & Proton-dependent oligopeptide transport (POT) family protein \\
\hline 247323_at & 4.02 & AT5G64170 & Dentin sialophosphoprotein-related \\
\hline 247224_at & 2.00 & AT5G65080 & AGL68/MAF5 (MADS AFFECTING FLOWERING 5) \\
\hline 245537_at & 3.57 & No_match & No_match \\
\hline
\end{tabular}

together, these phenotypes indicated that PAN might act to stabilize the developmental program of the shoot apex and thus buffers the impact of diverse environmental inputs.

Since the activity of the SAM is mainly determined by the WUS-CLV feedback system, which acts on the stem cell population, as well as the repression of differentiation throughout the meristem provided by STM, we investigated their regulatory and genetic interaction with PAN. Using in situ hybridization on serial histological sections, we first analyzed in detail the mRNAexpression patterns of PAN in the inflorescence meristem and found that, consistent with a buffering function, $P A N$ mRNA is most highly expressed in a ring-shaped domain surrounding the stem cells (Figures 2A-D). We detected weaker signals throughout the center of the SAM, suggesting that PAN might execute slightly different functions depending on expression levels. Similar to the situation identified for WUS, which was shown to bind to distinct cis-regulatory motifs with different affinity (Busch et al., 2010), these functions could be mediated by distinct sets of PAN downstream targets. However, in situ detection of PAN protein on sections of the SAM did not show the ring domain, but rather suggested that PAN is found throughout the meristem (Chuang et al., 1999). Unfortunately, we were unable to resolve whether these 
Table 2 | Genes with significantly reduced expression in inflorescence apices of pan mutants (Rank Products FDR 0.05).

\begin{tabular}{|c|c|c|c|}
\hline $\begin{array}{l}\text { Array } \\
\text { element }\end{array}$ & $\begin{array}{l}\text { Fold } \\
\text { change }\end{array}$ & $\begin{array}{l}\text { Locus } \\
\text { identifier }\end{array}$ & Annotation \\
\hline 259445_at & 0.54 & AT1G02400 & ATGA2OX6/DTA1 (GIBBERELLIN 2-OXIDASE 6); gibberellin 2-beta-dioxygenase \\
\hline 264521_at & 0.43 & AT1G10020 & $\begin{array}{l}\text { Similar to unknown protein [Arabidopsis thaliana] (TAIR:AT4G29310.1); similar to unnamed protein prod- } \\
\text { uct [Vitis vinifera] (GB:CAO61535.1); contains InterPro domain Protein of unknown function DUF1005 } \\
\text { (InterPro:IPR010410) }\end{array}$ \\
\hline 256098_at & 0.50 & AT1G13700 & Glucosamine/galactosamine-6-phosphate isomerase family protein \\
\hline 259466_at & 0.44 & AT1G19050 & ARR7 (RESPONSE REGULATOR 7); transcription regulator/two-component response regulator \\
\hline 260662_at & 0.49 & AT1G19540 & Isoflavone reductase. putative \\
\hline 260856_at & 0.46 & AT1G21910 & AP2 domain-containing transcription factor family protein \\
\hline 261926_at & 0.57 & AT1G22530 & PATL2; transporter \\
\hline 255742_at & 0.42 & AT1G25560 & AP2 domain-containing transcription factor. putative \\
\hline 265158_at & 0.58 & AT1G31040 & Zinc ion binding \\
\hline 261193_at & 0.51 & AT1G32920 & Similar to unknown protein [Arabidopsis thaliana] (TAIR:AT1G32928.1) \\
\hline 262010_at & 0.51 & AT1G35612 & Transposable element gene \\
\hline 260754_at & 0.56 & AT1G49000 & $\begin{array}{l}\text { Similar to unknown protein [Arabidopsis thaliana] (TAIR:AT3G18560.1); similar to hypothetical protein [Vitis } \\
\text { vinifera] (GB:CAN78728.1); similar to unnamed protein product [Vitis vinifera] (GB:CAO68009.1) }\end{array}$ \\
\hline 262399_at & 0.34 & AT1G49500 & Similar to unknown protein [Arabidopsis thaliana] (TAIR:AT3G19030.1) \\
\hline 262154_at & 0.47 & AT1G52700 & Phospholipase/carboxylesterase family protein \\
\hline 262226_at & 0.57 & $\begin{array}{l}\text { AT1G53885; } \\
\text { AT1G53903 }\end{array}$ & $\begin{array}{l}\text { [AT1G53885. senescence-associated protein-related]; [AT1G53903. similar to senescence-associated protein- } \\
\text { related [Arabidopsis thaliana] (TAIR:AT1G53885.1); similar to Protein of unknown function DUF581 [Med- } \\
\text { icago truncatula] (GB:ABO84791.1); contains InterPro domain Protein of unknown function DUF581 (Inter- } \\
\text { Pro:IPR007650)] }\end{array}$ \\
\hline 262278_at & 0.03 & AT1G68640 & PAN (PERIANTHIA); DNA binding/transcription factor \\
\hline 264704_at & 0.49 & AT1G70090 & $\begin{array}{l}\text { GATL9/LGT8 (Galacturonosyltransferase-like 9); polygalacturonate 4-alpha-galacturonosyltransferase/ } \\
\text { transferase. transferring glycosyl groups/transferase. transferring hexosyl groups }\end{array}$ \\
\hline 259751_at & 0.25 & AT1G71030 & ATMYBL2 (Arabidopsis myb-like 2); DNA binding/transcription factor \\
\hline 260427_at & 0.47 & AT1G72430 & Auxin-responsive protein-related \\
\hline 245777_at & 0.50 & AT1G73540 & ATNUDT21 (Arabidopsis thaliana Nudix hydrolase homolog 21); hydrolase \\
\hline 262212_at & 0.32 & AT1G74890 & ARR15 (RESPONSE REGULATOR 15); transcription regulator \\
\hline 261109_at & 0.36 & AT1G75450 & CKX5 (CYTOKININ OXIDASE 5); cytokinin dehydrogenase \\
\hline 259979_at & 0.56 & AT1G76600 & $\begin{array}{l}\text { Similar to unknown protein [Arabidopsis thaliana] (TAIR:AT1G21010.1); similar to hypothetical protein [Vitis } \\
\text { vinifera] (GB:CAN67638.1) }\end{array}$ \\
\hline 264299_s_at & 0.41 & $\begin{array}{l}\text { AT1G78850; } \\
\text { AT1G78860 }\end{array}$ & $\begin{array}{l}\text { [AT1G78850. curculin-like (mannose-binding) lectin family protein];[AT1G78860. curculin-like (mannose- } \\
\text { binding) lectin family protein] }\end{array}$ \\
\hline 262049_at & 0.58 & AT1G80180 & $\begin{array}{l}\text { Similar to unknown protein [Arabidopsis thaliana] (TAIR:AT1G15400.2); similar to unknown protein [Arabidopsis } \\
\text { thaliana] (TAIR:AT1G15400.3); similar to unknown protein [Arabidopsis thaliana] (TAIR:AT1G15400.1); similar } \\
\text { to hypothetical protein MtrDRAFT_AC148340g12v2 [Medicago truncatula] (GB:ABD28396.1) }\end{array}$ \\
\hline
\end{tabular}


Table 2 | Continued

\begin{tabular}{|c|c|c|c|}
\hline $\begin{array}{l}\text { Array } \\
\text { element }\end{array}$ & $\begin{array}{l}\text { Fold } \\
\text { change }\end{array}$ & $\begin{array}{l}\text { Locus } \\
\text { identifier }\end{array}$ & Annotation \\
\hline 260287_at & 0.39 & AT1G80440 & Kelch repeat-containing F-box family protein \\
\hline 265511_at & 0.16 & AT2G05540 & Glycine-rich protein \\
\hline 265475_at & 0.51 & AT2G15620 & NIR1 (NITRITE REDUCTASE); ferredoxin-nitrate reductase \\
\hline 267265_at & 0.51 & AT2G22980 & SCPL13; serine carboxypeptidase \\
\hline 245084_at & 0.39 & AT2G23290 & AtMYB70 (myb domain protein 70); DNA binding/transcription factor \\
\hline 266259_at & 0.50 & AT2G27830 & $\begin{array}{l}\text { Similar to pentatricopeptide (PPR) repeat-containing protein [Arabidopsis thaliana] (TAIR:AT4G22760.1); similar } \\
\text { to hypothetical protein [Catharanthus roseus] (GB:CAC09928.1) }\end{array}$ \\
\hline 267497_at & 0.40 & AT2G30540 & Glutaredoxin family protein \\
\hline 267093_at & 0.50 & AT2G38170 & CAX1 (CATION EXCHANGER 1); calcium ion transmembrane transporter/calcium:hydrogen antiporter \\
\hline 267034_at & 0.57 & AT2G38310 & $\begin{array}{l}\text { Similar to unknown protein [Arabidopsis thaliana] (TAIR:AT5G05440.1); similar to unnamed protein product } \\
\text { [Vitis vinifera] (GB:CAO48777.1); contains InterPro domain Bet v I allergen; (InterPro:IPR000916); contains } \\
\text { InterPro domain Streptomyces cyclase/dehydrase (InterPro:IPR005031) }\end{array}$ \\
\hline 267013_at & 0.56 & AT2G39180 & Protein kinase family protein \\
\hline 267623_at & 0.55 & AT2G39650 & $\begin{array}{l}\text { Similar to unknown protein [Arabidopsis thaliana] (TAIR:AT4G14620.1); similar to unnamed protein prod- } \\
\text { uct [Vitis vinifera] (GB:CAO69213.1); contains InterPro domain Protein of unknown function DUF506. plant } \\
\text { (InterPro:IPR006502) }\end{array}$ \\
\hline 267357_at & 0.57 & AT2G40000 & $\begin{array}{l}\text { Similar to unknown protein [Arabidopsis thaliana] (TAIR:AT3G55840.1); similar to unnamed protein product } \\
\text { [Vitis vinifera] (GB:CAO41329.1); contains InterPro domain Hs1 pro-1. C-terminal (InterPro:IPR009743); contains } \\
\text { InterPro domain Hs1pro-1. N-terminal (InterPro:IPR009869) }\end{array}$ \\
\hline 258704_at & 0.47 & AT3G09780 & Protein kinase family protein \\
\hline 256283_at & 0.52 & AT3G12540 & $\begin{array}{l}\text { Similar to unknown protein [Arabidopsis thaliana] (TAIR:AT2G39690.1); similar to At3g12540-like protein } \\
\text { [Boechera stricta] (GB:ABB89771.1); contains InterPro domain Protein of unknown function DUF547 (Inter- } \\
\text { Pro:IPR006869) }\end{array}$ \\
\hline 258252_at & 0.52 & AT3G15720 & Glycoside hydrolase family 28 protein/polygalacturonase (pectinase) family protein \\
\hline 257076_at & 0.40 & AT3G19680 & $\begin{array}{l}\text { Similar to unknown protein [Arabidopsis thaliana] (TAIR:AT1G50040.1); similar to unnamed protein prod- } \\
\text { uct [Vitis vinifera] (GB:CAO61535.1); contains InterPro domain Protein of unknown function DUF1005 } \\
\text { (InterPro:IPR010410) }\end{array}$ \\
\hline 257939_at & 0.37 & AT3G19930 & STP4 (SUGARTRANSPORTER 4); carbohydrate transmembrane transporter/sugar:hydrogen ion symporter \\
\hline 257985_at & 0.57 & AT3G20810 & Transcription factor jumonji (jmjC) domain-containing protein \\
\hline 257254_at & 0.53 & AT3G21950 & S-adenosyl-I-methionine:carboxyl methyltransferase family protein \\
\hline 256766_at & 0.45 & AT3G22231 & PCC1 (PATHOGEN AND CIRCADIAN CONTROLLED 1) \\
\hline 256617_at & 0.55 & AT3G22240 & Unknown protein \\
\hline 258447_at & 0.54 & AT3G22450 & Structural constituent of ribosome \\
\hline 258125_s_at & 0.57 & $\begin{array}{l}\text { AT3G23530; } \\
\text { AT3G23510 }\end{array}$ & $\begin{array}{l}\text { [AT3G23530. cyclopropane fatty acid synthase. putative/CPA-FA synthase. putative];[AT3G23510. cyclo- } \\
\text { propane fatty acid synthase. putative/CPA-FA synthase. putative] }\end{array}$ \\
\hline 252679_at & 0.55 & AT3G44260 & CCR4-NOT transcription complex protein. putative \\
\hline 252374_at & 0.55 & AT3G48100 & ARR5 (ARABIDOPSIS RESPONSE REGULATOR 5); transcription regulator/two-component response regulator \\
\hline
\end{tabular}


Table 2 | Continued

\begin{tabular}{|c|c|c|c|}
\hline $\begin{array}{l}\text { Array } \\
\text { element }\end{array}$ & $\begin{array}{l}\text { Fold } \\
\text { change }\end{array}$ & $\begin{array}{l}\text { Locus } \\
\text { identifier }\end{array}$ & Annotation \\
\hline 252193_at & 0.48 & AT3G50060 & MYB77; DNA binding/transcription factor \\
\hline 251791_at & 0.25 & AT3G55500 & ATEXPA16 (ARABIDOPSIS THALIANA EXPANSIN A16) \\
\hline 251745_at & 0.57 & AT3G55980 & Zinc finger (CCCH-type) family protein \\
\hline 251575_at & 0.55 & AT3G58120 & bZIP transcription factor family protein \\
\hline 255255_at & 0.56 & AT4G05070 & Unknown protein \\
\hline 255064_at & 0.32 & AT4G08950 & Phosphate-responsive protein. putative (EXO) \\
\hline 254926_at & 0.53 & AT4G11280 & ACS6 (1-AMINOCYCLOPROPANE-1-CARBOXYLIC ACID (ACC) SYNTHASE 6) \\
\hline 254665_at & 0.52 & AT4G18340 & Glycosyl hydrolase family 17 protein \\
\hline 254098_at & 0.55 & AT4G25100 & FSD1 (FE SUPEROXIDE DISMUTASE 1); iron superoxide dismutase \\
\hline 254057_at & 0.53 & AT4G25170 & $\begin{array}{l}\text { Similar to unknown protein [Arabidopsis thaliana] (TAIR:AT5G61490.1); similar to unnamed protein product } \\
\text { [Vitis vinifera] (GB:CAO60860.1); contains InterPro domain uncharacterized conserved protein UCP012943 } \\
\text { (InterPro:IPR016606) }\end{array}$ \\
\hline 253915_at & 0.17 & AT4G27280 & Calcium-binding EF hand family protein \\
\hline 253666_at & 0.35 & AT4G30270 & MERI5B (MERISTEM-5); hydrolase. acting on glycosyl bonds/xyloglucan:xyloglucosyl transferase \\
\hline 253421_at & 0.56 & AT4G32340 & Binding \\
\hline 253439_at & 0.50 & AT4G32540 & YUC (YUCCA); FAD binding/NADP binding/flavin-containing monooxygenase/monooxygenase/oxidoreductase \\
\hline 253317_at & 0.53 & AT4G33960 & Similar to unknown protein [Arabidopsis thaliana] (TAIR:AT2G15830.1) \\
\hline 250777_at & 0.42 & AT5G05440 & $\begin{array}{l}\text { Similar to unknown protein [Arabidopsis thaliana] (TAIR:AT2G38310.1); similar to unnamed protein product } \\
\text { [Vitis vinifera] (GB:CAO48777.1); contains InterPro domain Bet v I allergen; (InterPro:IPR000916); contains } \\
\text { InterPro domain Streptomyces cyclase/dehydrase (InterPro:IPR005031) }\end{array}$ \\
\hline 250389_at & 0.51 & AT5G11320 & YUC4 (YUCCA4); monooxygenase \\
\hline 250344_at & 0.29 & AT5G11930 & Glutaredoxin family protein \\
\hline 246520_at & 0.06 & AT5G15790 & Zinc finger (C3HC4-type RING finger) family protein \\
\hline 246531_at & 0.40 & AT5G15800 & SEP1 (SEPALLATA1); DNA binding/transcription factor \\
\hline 249996_at & 0.36 & AT5G18600 & Glutaredoxin family protein \\
\hline 246700_at & 0.54 & AT5G28030 & Cysteine synthase. putative/O-acetylserine (thiol)-lyase. putative/O-acetylserine sulfhydrylase. putative \\
\hline 249645_at & 0.39 & AT5G36910 & THI2.2 (THIONIN 2.2); toxin receptor binding \\
\hline 256356_s_at & 0.58 & $\begin{array}{l}\text { AT5G43620; } \\
\text { AT1G66500 }\end{array}$ & [AT5G43620. S-locus protein-related];[AT1G66500. zinc finger (C2H2-type) family protein] \\
\hline 248865_at & 0.57 & AT5G46790 & $\begin{array}{l}\text { Similar to unknown protein [Arabidopsis thaliana] (TAIR:AT4G17870.1); similar to Streptomyces } \\
\text { cyclase/dehydrase family protein [Brassica oleracea] (GB:ABD65631.1); contains InterPro domain Strepto- } \\
\text { myces cyclase/dehydrase (InterPro:IPR005031) }\end{array}$ \\
\hline 248163_at & 0.49 & AT5G54510 & DFL1/GH3.6 (DWARF IN LIGHT 1); indole-3-acetic acid amido synthetase \\
\hline 248020_at & 0.46 & AT5G56490 & FAD-binding domain-containing protein \\
\hline 247956_at & 0.47 & AT5G56970 & CKX3 (CYTOKININ OXIDASE 3); cytokinin dehydrogenase \\
\hline
\end{tabular}


Table 2 | Continued

\begin{tabular}{|c|c|c|c|}
\hline $\begin{array}{l}\text { Array } \\
\text { element }\end{array}$ & $\begin{array}{l}\text { Fold } \\
\text { change }\end{array}$ & $\begin{array}{l}\text { Locus } \\
\text { identifier }\end{array}$ & Annotation \\
\hline 247925_at & 0.13 & AT5G57560 & TCH4 (TOUCH 4); hydrolase. acting on glycosyl bonds/xyloglucan:xyloglucosyl transferase \\
\hline 247649_at & 0.48 & AT5G60030 & $\begin{array}{l}\text { Similar to unknown protein [Arabidopsis thaliana] (TAIR:AT1G75335.1); similar to hypothetical protein [Vitis } \\
\text { vinifera] (GB:CAN66187.1) }\end{array}$ \\
\hline 247668_at & 0.53 & AT5G60100 & APRR3 (PSEUDO-RESPONSE REGULATOR 3); transcription regulator \\
\hline 247540_at & 0.17 & AT5G61590 & AP2 domain-containing transcription factor family protein \\
\hline 247543_at & 0.21 & AT5G61600 & Ethylene-responsive element-binding family protein \\
\hline 247406_at & 0.58 & AT5G62920 & ARR6 (RESPONSE REGULATOR 6); transcription regulator/two-component response regulator \\
\hline 246987_at & 0.21 & AT5G67300 & ATMYB44/ATMYBR1/MYBR1 (MYB DOMAIN PROTEIN 44); DNA binding/transcription factor \\
\hline 244994_at & 0.53 & ATCG01010 & Chloroplast encoded NADH dehydrogenase unit. \\
\hline
\end{tabular}

differences were of technical nature, or reflected relevant biology. Hybridizations on cross sections demonstrated that PAN mRNA is strongly reduced even in early organ primordia (Figures $2 \mathbf{E}-\mathbf{H}$ ). We next investigated how the SAM regulatory system is affected by the loss-of PAN function. First, we noticed that the SAM was significantly increased in size (Figures 2I,M) and that the WUS expression domain is substantially wider compared to the wildtype situation (Figures 2J,N). Interestingly, the stem cell domain marked by CLV3 expression remained largely unaffected despite the expanded stem cell niche (Figures $2 \mathbf{K}, \mathbf{O}$ ), suggesting that the regulatory interaction between WUS and CLV3 is partially uncoupled in pan mutants. In line with the enlarged meristem, we found expanded STM expression in pan apices (Figures $2 \mathbf{L}, \mathbf{P}$ ) and the absence of STM transcripts from emerging organ primordia was less pronounced in pan when compared to wild-type. Taken together, these results demonstrate that $P A N$ function is required for normal SAM development, which might be mediated by its effects on the expression of the canonical meristem regulators. To address how PAN is integrated into the regulatory network of the SAM, we analyzed its expression in wus and $c l v 3$ mutants, which represent the extremes in meristem dis-regulation. Since wus mutants rarely form inflorescence meristems, we focused our analysis on the seedling stage and found accumulation of PAN mRNA mostly in the center of the SAM in wild-type. In addition, we detected weaker signals on the periphery of the meristem and at the adaxial sides of young leaves (Figure 2Q). Consistent with the loss-of a fully developed SAM in wus, we were unable to detect $P A N$ transcripts in central tissue of this mutant, however, strong expression was found in leaf-primordia and young leaves (Figure 2R). While Chuang et al. (1999) had reported that $P A N$ protein expression is mostly independent of $C L V 3$, we observed that $P A N$ transcripts accumulated throughout the SAM, with a ring of strong expression toward the base with weaker signals toward the top of the expanded $c l v 3$ meristem (Figures 2S,T).

Having shown that PAN is more tightly connected to the regulatory system of the SAM than previously anticipated, we extended our analysis to test the functional interaction of PAN with CLV3, WUS, and STM using genetics. Plants that carry mutations in CLV3 are characterized by an enlarged SAM, an increase in the number of lateral organs developing from the SAM and over-proliferation of floral meristems. When we combined the clv3-7 loss-of-function allele with pan, we observed a substantial enhancement of the $\operatorname{clv} 3$ phenotype (Figure 3A). Compared to $c l v 3$ single mutants, SAMs of pan $\operatorname{clv} 3$ double mutants were even further enlarged (arrowheads in Figures 3C,D) and developed even more lateral organs (Figures 3C,D). Consistent with an enhancement of meristem phenotypes by the pan mutation, we observed a drastic reduction SAM function when we combined wus and pan (Figure 3F). In contrast to wus mutants, which develop a bushy stature because of the stop and go phenotype of the meristem (Laux et al., 1996), stem cell activity in wus pan double mutants ceased after the formation of leaves and elongated shoots were never formed. Since CLV3 and WUS act in the same pathway and both showed synergistic genetic interactions with $P A N$, we next wondered how PAN would interact with STM, whose activity is independent of the WUS-CLV system. To our surprise we found that the stm phenotype was partially suppressed in pan stm double mutants, which developed a substantially larger number of lateral organs and shoots compared to stm plants (Figure 3G). In some cases we even observed flowers with a regular arrangement of floral organs, however these flowers remained sterile. Thus, while in the case of WUS and CLV3 PAN behaved as a molecular buffer, which is able to stabilize SAM function in the absence of other meristem regulators, this function was not observed when pan was combined with stm, suggesting that they have antagonistic activities.

To elucidate some of the mechanisms that could underlie these complex meristematic functions of PAN, we recorded the molecular phenotype of pan single mutants by transcript profiling. Wild-type and pan mutants were grown in LD for 25 days before we sampled two independent pools of 50 inflorescence meristems of each genotype by removing developing flowers older than stage 8. After Affymetrix Ath1 profiling we applied GC-RMA to normalize the data and derive expression values (Wu et al., 2004) followed by Rank Products to identify differentially expressed genes at a false discovery rate of 0.05 (Breitling et al., 2004). One hundred sixty transcripts showed increased abundance (Table 1), while 120 mRNAs were found to be significantly reduced in inflorescence apices of pan mutants compared to wild-type (Table 2). To obtain a first insight into the potential function of PAN downstream genes we used Gene Ontology (GO) analysis on the level of the annotation of biological function, as well as using molecular function as a readout. Interestingly, we found the "response to stimulus" category as highly enriched among the genes with increased as well as reduced expression. Among the increased 


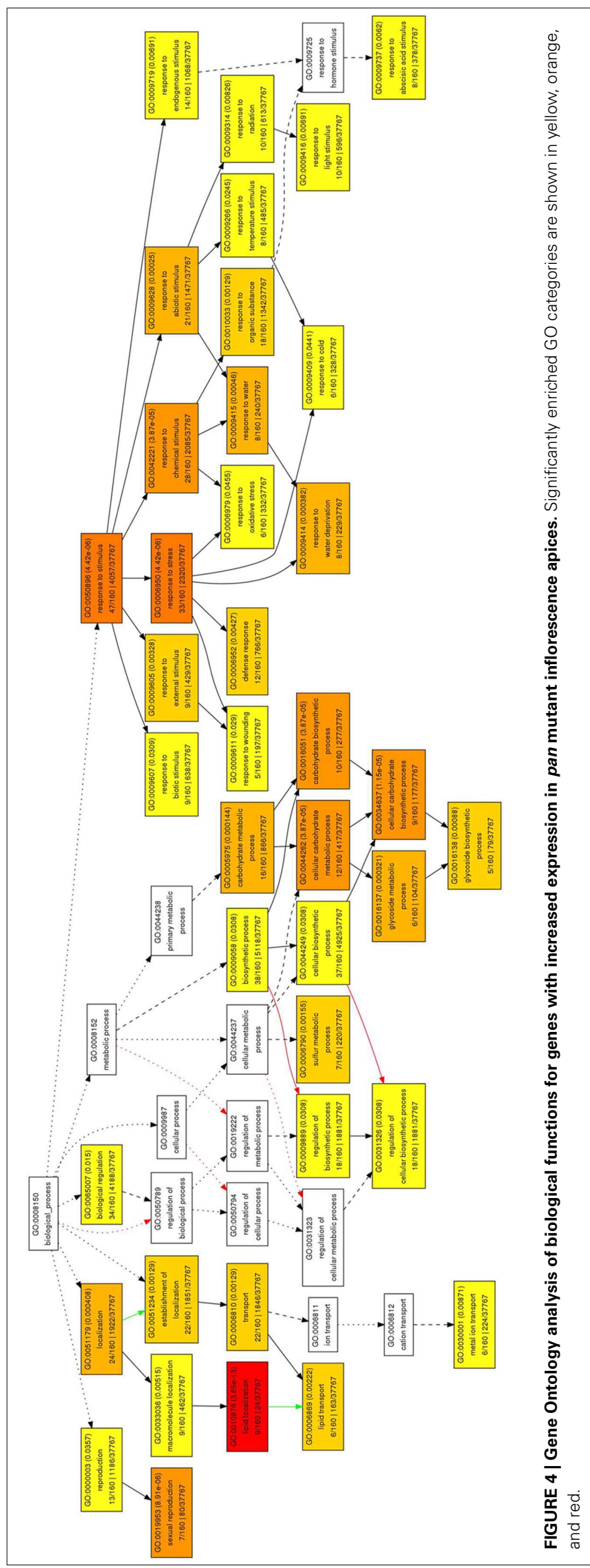

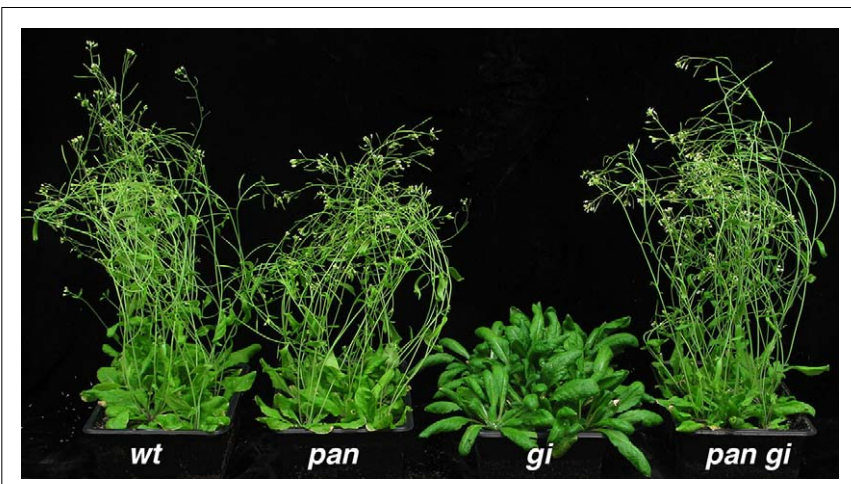

FIGURE 5 | Genetic interaction of PAN with $\mathbf{G l}$. Plants grown for 25 day under LD are shown.

mRNAs we found diverse functional sub-categories indicating that $P A N$ plays a role in stress and environmental response (Figure 4). A prominent example was GIGANTEA (GI), whose expression is controlled by the circadian clock and whose activity is necessary for normal clock function and promotion of flowering under LD (Fowler et al., 1999; Park et al., 1999). To test if GI plays a relevant role as PAN downstream gene, we created pan gi double mutants and compared them to the respective parental genotypes. Strikingly, we found that loss-of PAN function was able to fully suppress the late flowering phenotype of $g i$ mutants in LD (Figure 5), demonstrating that GI and PAN act in the same pathway.

In contrast to the rather diverse GO categories observed in the list of genes with increased expression, the reduced transcripts revealed a much more specific developmental signature. Among them we identified a substantial overrepresentation of genes with annotated functions in hormone signaling, specifically for gibberellin, ethylene, auxin and, most prominently, cytokinin response (Figure 6). This developmental signature was also apparent in the GO analysis for molecular functions with "transcription regulator activity" and "two-component response regulator activity" as the most overrepresented annotation terms (Figure 7). Twocomponent response regulators build the backbone of cytokinin signal transduction and response, with B-type ARRs acting as cytokinin dependent transcription factors directly upstream of Atype ARRs as immediate early cytokinin response genes with roles in negative feedback regulation (Werner and Schmülling, 2009). Strikingly, only the expression of A-type ARRs was affected in pan mutants and ARR4, ARR5, ARR6, ARR7, ARR15, and ARR16, were among the transcripts with significantly reduced abundance, a result which we independently confirmed using quantitative realtime RT-PCR (data not shown). In addition to cytokinin response genes, we identified two cytokinin oxidases, CKX3 and CKX5, as genes with reduced expression. Since CKX proteins irreversibly degrade cytokinin (Mok and Mok, 2001; Werner et al., 2003) and because A-type ARRs counteract cytokinin signaling (To et al., 2004), a reduction of their expression in pan mutants suggests that PAN acts to limit cytokinin activity in the SAM. This interpretation is consistent with the finding that SAM size is increased in pan mutants reminiscent of plants with increased cytokinin levels (Bartrina et al., 2011). In addition, we had previously identified 


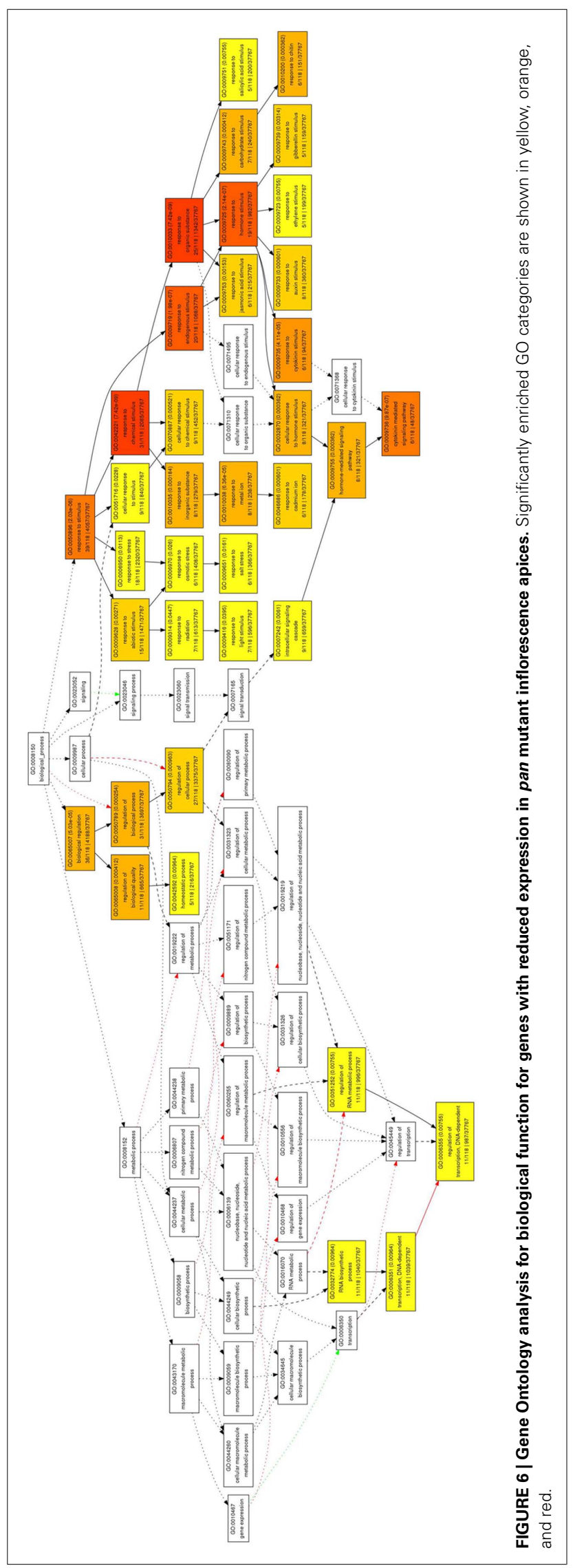

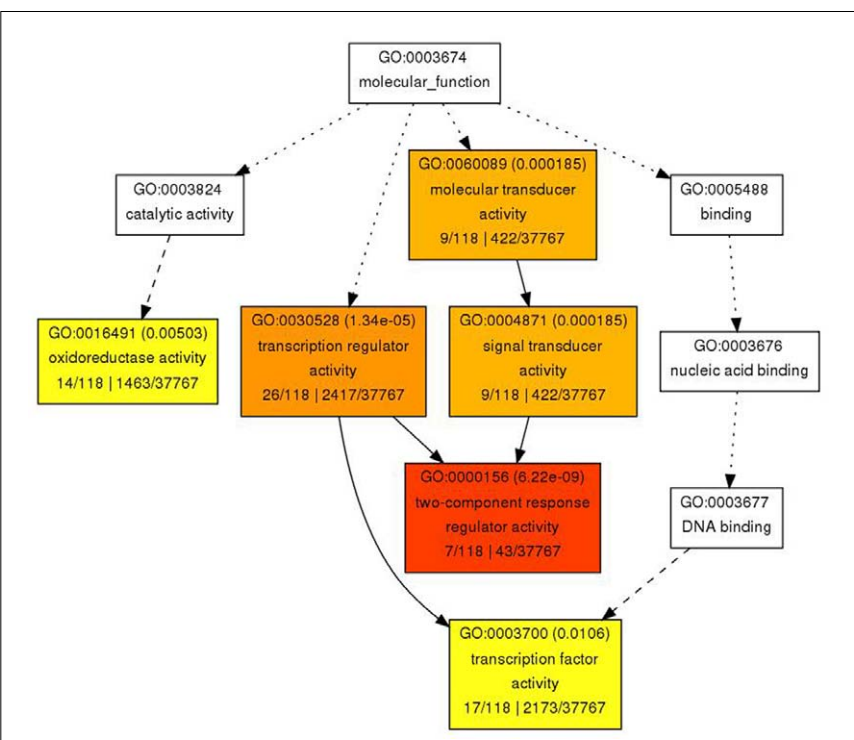

FIGURE 7 | Gene Ontology analysis for molecular function for genes with reduced expression in pan mutant inflorescence apices.

Significantly enriched GO categories are shown in yellow, orange, and red.

ARR5, ARR6, ARR7, and ARR15 as direct transcriptional targets of WUS, connecting these cytokinin response genes to the core regulatory system of the SAM. While from the list of genes with reduced expression an antagonistic interaction of $P A N$ and cytokinin could be deduced, it also suggested that $P A N$ acts to stimulate auxin signaling, since it contained YUCCA1 and YUCCA4, two genes coding for important auxin biosynthesis enzymes (Zhao et al., 2001). Since auxin directly represses transcription of $A R R 7$ and ARR15 via the Auxin Response Factor MONOPTEROS (Zhao et al., 2010) in the SAM, PAN could act on the expression of A-type ARRs in multiple independent pathways. Strikingly, WUS was identified among the transcriptional regulators with reduced expression, confirming that PAN is intimately connected to the SAM regulatory network.

Having identified cytokinin and auxin signaling as major downstream effector pathways of PAN we next addressed the functional relevance of these regulatory interactions using genetics. We focused our analysis on ARR7 and ARR15, since both of them were shown to have important meristematic functions (Leibfried et al., 2005; Zhao et al., 2010), and combined these mutants (Figures 8D,E) with pan (Figure 8B) and $c l v 3$ (Figure 8C) in double and triple mutant combinations. While single A-type arr mutants have no phenotypes or very mild ones (Figures 8D,E; To et al., 2004), combination of arr7 and arr 15 with pan lead to severe growth retardation (Figures 8G,H). Interestingly, while removing $C L V 3$ function in the pan background lead to massive over-proliferation and meristem expansion beyond the regular $c l v 3$ defect (Figures 3B-E), this phenotype was completely suppressed in the pan clv 3 arr 7 combination (Figures 8F-I). However, the growth retardation was only transient and pan arr 15 as well as pan arr $15 \mathrm{clv} 3$ plants recovered after about 2 weeks and developed plants with pentameric flowers, which closely resembled pan $\operatorname{clv} 3$ mutants. This capacity to overcome A-type ARR related 

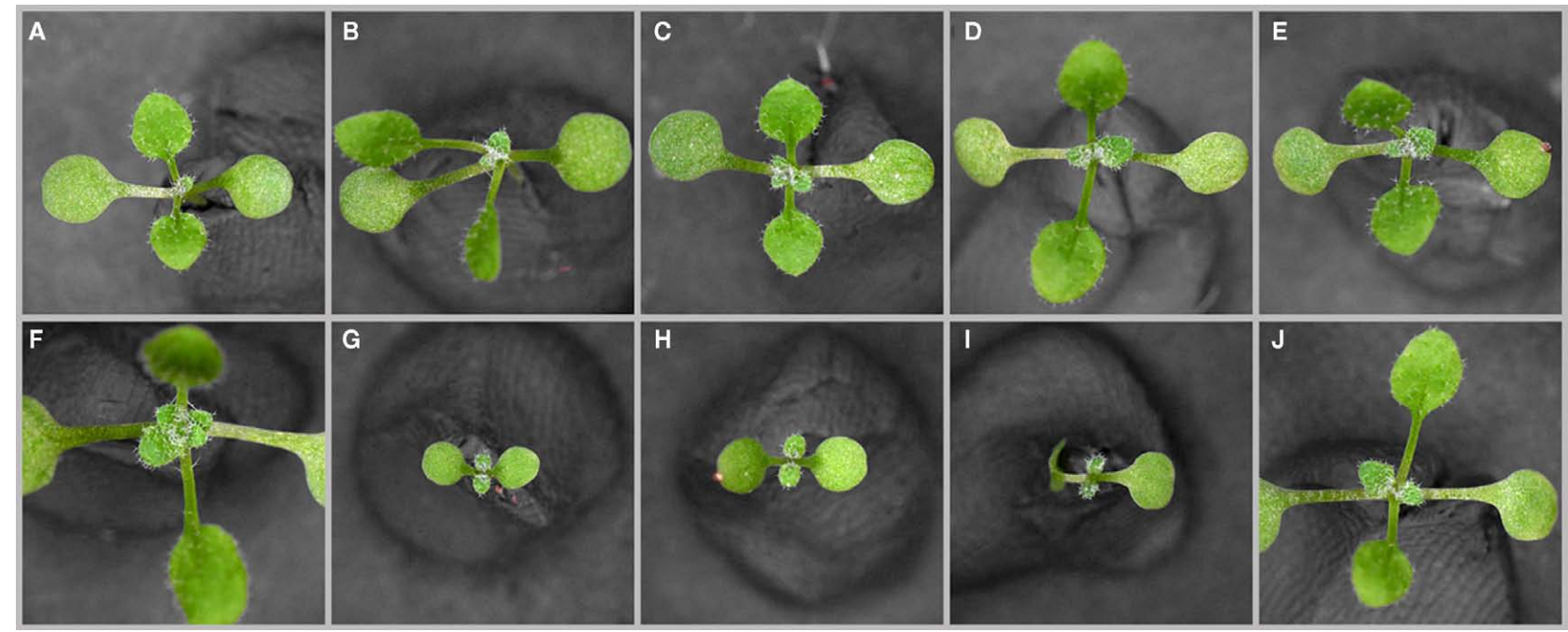

FIGURE 8 | Genetic interaction of PAN with Cytokinin Signaling Components ARR7, ARR15, and CLV3. Ten-days-old soil grown seedlings of wild-type (A) and pan (B), clv3 (C), arr15 (D), arr7 (E) pan clv3-7 (F), pan arr7 (G), pan arr15 (H), pan arr15 clv3 (I), and arr7 arr15 (J) mutant plants. All plants were grown under LD and representative seedlings are shown. developmental defects was also observed in plants carrying an over-activated form of ARR7 (Leibfried et al., 2005) and suggest that the cytokinin signaling system has a strong ability to adapt to perturbations. Mutation of multiple A-type ARRs, such as in an arr7 arr15 double mutant did not cause the phenotypes observed in the pan arr combinations (Figure 8J) underlining the important role of PAN in the SAM. Having observed a strong genetic interaction of PAN with components of the cytokinin response, we next tested its ability to modify auxin related defects. To this end we analyzed the interaction of PAN with PINFORMED-1 $(P I N 1)$, the major auxin efflux carrier responsible for generating local auxin maxima at the periphery of the SAM and thus organ initiation during shoot development (Gälweiler et al., 1998; Reinhardt et al., 2000). While pin1 mutants rarely developed flowers under our growth conditions (Figures 9A,C), pin1 pan double mutants exhibited a significantly increased number of flowers (Figures 9B,C), which were deformed and generally sterile. Again, as in the case of cytokinin signaling, these results demonstrated that $P A N$ is able to modulate auxin dependent developmental functions, in line with the hypothesis that PAN might act as a multifunctional hub for diverse meristematic functions.

\section{SUMMARY AND OUTLOOK}

Taken together, we have shown here by molecular phenotyping and genetics that PAN is connected to a plethora of diverse input pathways and may act as an integrator to buffer shoot meristem activity. PAN inputs include pathways for environmental sensing, such as day-length and other abiotic factors, as well as hard-wired developmental circuitries, such as the WUS-CLV system. Strikingly, the same holds true for the PAN output network, which we found to include components of the circadian clock and stress response as examples for modulating environmental interactions. Furthermore, PAN downstream genes showed a strong developmental signature, which was most apparently represented by a number of plant hormone signaling systems. Based on our results we suggest that PAN might act as a node between cytokinin and auxin signaling pathways, with cytokinin outputs being repressed and auxin activity being induced by PAN. PAN is a member of the D-class of bZIP transcription factors (Jakoby et al., 2002) and thus groups with the TGA regulators, which are involved in mediating pathogen defense (Zander et al., 2010). The sequence similarity of PAN and TGA pathogen response regulators suggests that PAN function might have evolved from an environmental surveillance activity, which was enhanced to include developmental roles to give rise to an integrated buffering system.

\section{MATERIALS AND METHODS PLANT MATERIAL}

Arabidopsis thaliana plants of the Columbia (Col-0) background were grown on soil at $23^{\circ} \mathrm{C}$. Analyses were performed after growth under three different light conditions: CL, LD (16 h of light), or SD ( $8 \mathrm{~h}$ light) for 10 days for seedlings and 25 days for vegetative and reproductive tissues if not noted otherwise. The following mutant alleles used: arr7 (At1G19050): WiscDsLox485-488B15; arr15 (At1G74890): WiscDSLox334D02; clv3 (At2G27250): clv3-7; pan (AT1G68640): Salk N557190; wus (At2G17950): wus-4 in Columbia background (wus-mh; Leibfried et al., 2005); stm (At1G62360): GABI-Kat line 100F11; pin1 (At1G73590): GABI-Kat line 051A10; gi (At1G22770): gi-201. Phenotypic characterizations were carried out by growing mutants and controls at least three times independently and analyzing a total of at least 30 individuals for each genotype. Representative plants are shown.

\section{IN SITU HYBRIDIZATIONS}

Plant material was fixed and embedded using a Leica ASP300 and hybridized following standard protocols (Weigel and Glazebrook, 2002) adding $10 \%$ polyvinylalcohol (PVA) to the staining solution. Digoxigenin-labeled full-length RNA riboprobes were synthesized 

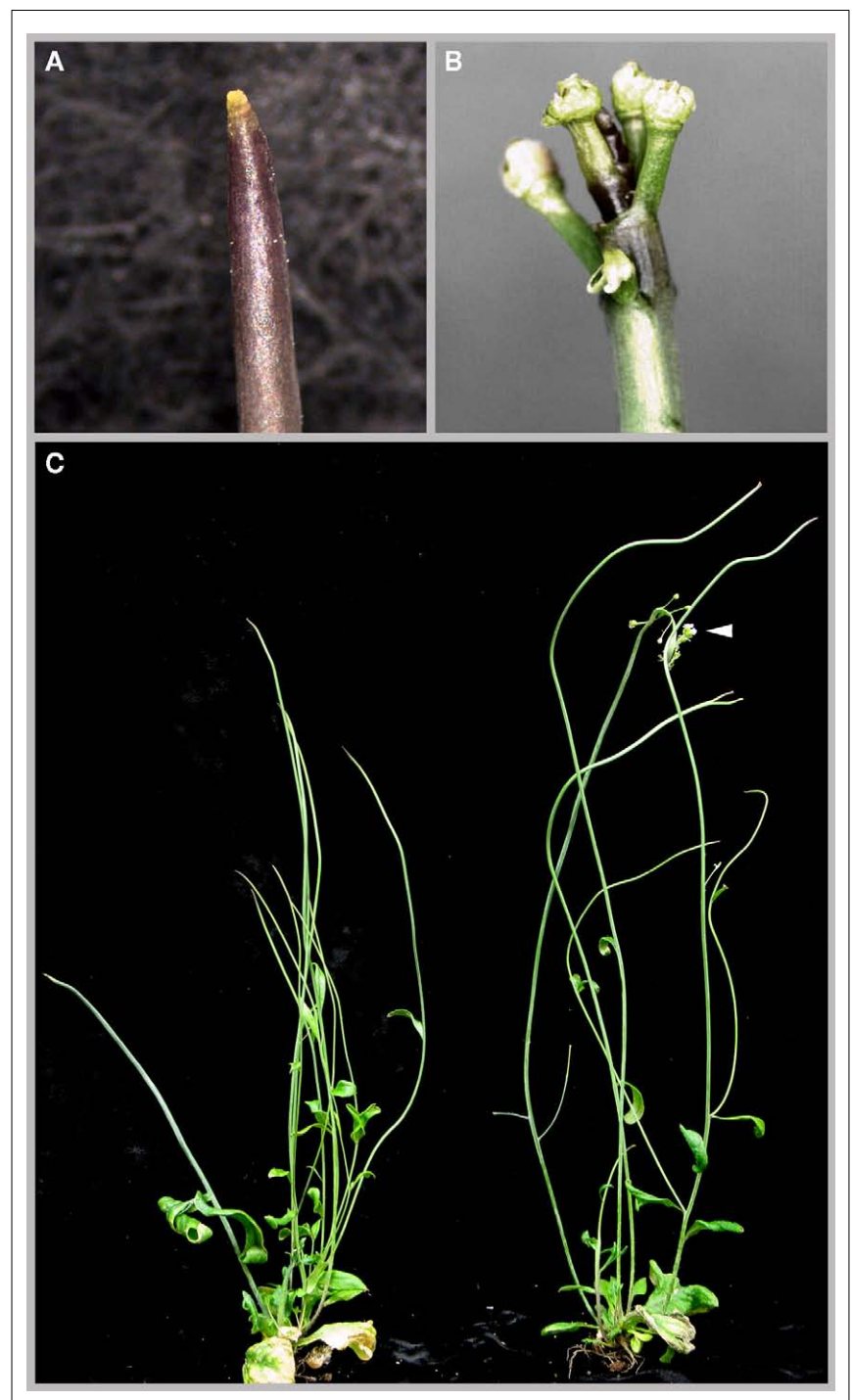

FIGURE 9 | Genetic interaction of PAN with PIN1. Primary shoot of pin 1 mutant (A) and pan pin 1 double mutant (B) and whole plant comparison (C) of pin 1 (left) and pan pin1 (right) showing increased development of floral buds on the primary shoot of the pan pin 1 double mutant. for CLV3 (At2G27250), PAN (AT1G68640), STM (At1G62360), and WUS (At2G17950) as described in Geier et al. (2008) and Maier et al. (2009) according to the manufacturer instruction (Roche).

\section{MICROARRAY EXPERIMENTS}

Pools of 50 microscopically dissected inflorescence apices of pan mutants and wild-type both carrying the KB14 AG::GUS reporter gene (Busch et al., 1999; Lohmann et al., 2001) were grown for 25 days in LD conditions and profiled in duplicate using the Affymetrix ATH1 platform. RNA extraction and microarray analyses were performed as described (Schmid et al., 2005; Buechel et al., 2010). Expression estimates were derived by GC-RMA (Wu et al., 2004) at standard settings implemented in R. We determined significant changes on a per-gene level by applying the Rank products algorithm (Breitling et al., 2004) using 100 permutations and a false discovery rate cut-off of $5 \%$. GO analysis was carried out using AgriGO (Du et al., 2010).

\section{QUANTITATIVE REAL-TIME PCR}

Total RNA was extracted from apices of plants grown in an independent experiment using RNeasy Mini columns with on-column DNAse digestion (Qiagen). Reverse transcription was performed with $1 \mu \mathrm{g}$ of total RNA, using a Reverse Transcription Kit (Fermentas). PCR amplification was carried out in the presence of the double-strand DNA-specific dye SYBR Green (Molecular Probes) using intron spanning primers (Andersen et al., 2008). Amplification was monitored in real-time with the Opticon Continuous Fluorescence Detection System (MJR). BETA-TUBULIN-2 transcript levels served to normalize mRNA measurements.

\section{ACKNOWLEDGMENTS}

We thank Patrice Salome for seeds of the gi-201 mutant, Martin Vötsch for support in preparing figures, Sascha Laubinger for discussion and Gerd Jürgens and Detlef Weigel for continuous support and discussion. This work was supported by fellowships from the Konrad Adenauer Stiftung (Annette T. Maier) DFGAFGN grant LO1450/2-1 (Jan U. Lohmann), as well as funds from the EMBO Young Investigator Program and the HFSP Career Development Award to Jan U. Lohmann, and the Max Planck Society.

\section{REFERENCES}

Andersen, S. U., Buechel, S., Zhao, Z., Ljung, K., Novak, O., Busch, W., Schuster, C., and Lohmann, J. U. (2008). Requirement of B2-type cyclin-dependent kinases for meristem integrity in Arabidopsis thaliana. Plant Cell 20, 88-100.

Barton, M., and Poethig, R. (1993). Formation of the shoot apical meristem in Arabidopsis thaliana - an analysis of development in the wild-type and in the shoot meristemless mutant. Development 119, 823-831.

Barton, M. K. (2010). Twenty years on: the inner workings of the shoot apical meristem, a developmental dynamo. Dev. Biol. 341, 95-113.
Bartrina, I., Otto, E., Strnad, M., Werner, T., and Schmülling, T. (2011). Cytokinin regulates the activity of reproductive meristems, flower organ size, ovule formation, and thus seed yield in Arabidopsis thaliana. Plant Cell 23, 69-80.

Brand, U., Fletcher, J. C., Hobe, M., Meyerowitz, E. M., and Simon, R. (2000). Dependence of stem cell fate in Arabidopsis on a feedback loop regulated by CLV3 activity. Science 289, 617-619.

Breitling, R., Armengaud, P., Amtmann, A., and Herzyk, P. (2004). Rank products: a simple, yet powerful, new method to detect differentially regulated genes in replicated microarray experiments. FEBS Lett. 573, 83-92.

Buechel, S., Leibfried, A., To, J. P. C., Zhao, Z., Andersen, S. U., Kieber, J. J., and Lohmann, J. U. (2010). Role of A-type Arabidopsis response regulators in meristem maintenance and regeneration. Eur. J. Cell Biol. 89, 279-284.

Busch, M. A., Bomblies, K., and Weigel, D. (1999). Activation of a floral homeotic gene in Arabidopsis. Science 285, 585-587.

Busch, W., Miotk, A., Ariel, F. D., Zhao, Z., Forner, J., Daum, G., Suzaki, T., Schuster, C., Schultheiss, S. J., Leibfried, A., Haubeiss, S., Ha, N., Chan, R. L., and Lohmann, J. U.
(2010). Transcriptional control of a plant stem cell niche. Dev. Cell 18, 849-861.

Chuang, C. F., Running, M. P., Williams, R. W., and Meyerowitz, E. M. (1999). The PERIANTHIA gene encodes a bZIP protein involved in the determination of floral organ number in Arabidopsis thaliana. Genes Dev. 13, 334-344.

Clark, S. E., Running, M. P., and Meyerowitz, E. M. (1993). CLAVATA1, a regulator of meristem and flower development in Arabidopsis. Development 119, 397-418.

Clark, S. E., Running, M. P., and Meyerowitz, E. M. (1995). 
CLAVATA3 is a specific regulator of shoot and floral meristem development affecting the same processes as CLAVATA1. Development 121, 2057-2067.

Das, P., Ito, T., Wellmer, F., Vernoux, T., Dedieu, A., Traas, J., and Meyerowitz, E. M. (2009). Floral stem cell termination involves the direct regulation of AGAMOUS by PERIANTHIA. Development 136, 1605-1611.

Du, Z., Zhou, X., Ling, Y., Zhang, Z., and $\mathrm{Su}, \mathrm{Z}$. (2010). agriGO: a GO analysis toolkit for the agricultural community. Nucleic Acids Res. 38, W64-W70.

Fowler, S., Lee, K., Onouchi, H., Samach, A., Richardson, K., Morris, B., Coupland, G., and Putterill, J. (1999). GIGANTEA: a circadian clock-controlled gene that regulates photoperiodic flowering in Arabidopsis and encodes a protein with several possible membranespanning domains. EMBO J. 18, 4679-4688.

Furutani, M., Vernoux, T., Traas, J., Kato, T., Tasaka, M., and Aida, M. (2004). PIN-FORMED1 and PINOID regulate boundary formation and cotyledon development in Arabidopsis embryogenesis. Development 131, 5021-5030.

Gälweiler, L., Guan, C., Müller, A., Wisman, E., Mendgen, K., Yephremov, A., and Palme, K. (1998). Regulation of polar auxin transport by AtPIN1 in Arabidopsis vascular tissue. Science 282, 2226-2230.

Geier, F., Lohmann, J. U., Gerstung, M., Maier, A. T., Timmer, J., and Fleck, C. (2008). A quantitative and dynamic model for plant stem cell regulation. PLoS ONE 3, e3553. doi:10.1371/journal.pone.0003553

Hepworth, S. R., Zhang, Y., McKim, S., Li, X., and Haughn, G. W. (2005). BLADE-ON-PETIOLE-dependent signaling controls leaf and floral patterning in Arabidopsis. Plant Cell 17, 1434-1448.

Jakoby, M., Weisshaar, B., Dröge-Laser, W., Vicente-Carbajosa, J., Tiedemann, J., Kroj, T., Parcy, F., and bZIP Research Group. (2002). bZIP transcription factors in Arabidopsis. Trends Plant Sci. 7, 106-111.

Jasinski, S., Piazza, P., Craft, J., Hay, A., Woolley, L., Rieu, I., Phillips, A., Hedden, P., and Tsiantis, M.
(2005). KNOX action in Arabidopsis is mediated by coordinate regulation of cytokinin and gibberellin activities. Curr. Biol. 15, 1560-1565.

Kayes, J. M., and Clark, S. E. (1998). CLAVATA2, a regulator of meristem and organ development in Arabidopsis. Development 125, 3843-3851.

Laux, T., Mayer, K. F., Berger, J., and Jürgens, G. (1996). The WUSCHEL gene is required for shoot and floral meristem integrity in Arabidopsis. Development 122, 87-96.

Leibfried, A., To, J. P. C., Busch, W., Stehling, S., Kehle, A., Demar, M., Kieber, J. J., and Lohmann, J. U. (2005). WUSCHEL controls meristem function by direct regulation of cytokinin-inducible response regulators. Nature 438, 1172-1175.

Lohmann, J. U., Hong, R. L., Hobe, M., Busch, M. A., Parcy, F., Simon, R., and Weigel, D. (2001). A molecular link between stem cell regulation and floral patterning in Arabidopsis. Cell 105, 793-803.

Long, J. A., Moan, E. I., Medford, J. I., and Barton, M. K. (1996). A member of the KNOTTED class of homeodomain proteins encoded by the STM gene of Arabidopsis. Nature 379, 66-69.

Maier, A. T., Stehling-Sun, S., Wollmann, H., Demar, M., Hong, R. L., Haubeiss, S., Weigel, D., and Lohmann, J. U. (2009). Dual roles of the bZIP transcription factor PERIANTHIA in the control of floral architecture and homeotic gene expression. Development 136, 1613-1620

Mayer, K. F., Schoof, H., Haecker, A., Lenhard, M., Jürgens, G., and Laux, T. (1998). Role of WUSCHEL in regulating stem cell fate in the Arabidopsis shoot meristem. Cell 95, 805-815.

Mok, D. W., and Mok, M. C. (2001). Cytokinin metabolism and action. Annu. Rev. Plant Physiol. Plant Mol. Biol. 52, 89-118.

Parcy, F., Nilsson, O., Busch, M. A., Lee, I., and Weigel, D. (1998). A genetic framework for floral patterning. Nature 395, 561-566.

Park, D. H., Somers, D. E., Kim, Y.-S., Choy, Y. H., Lim, H. K., Soh, M. S., Kim, H. J., Kay, S. A., and Nam,
H. G. (1999). Control of circadian rhythms and photoperiodic flowering by the Arabidopsis GIGANTEA gene. Science 285, 1579-1582.

Reinhardt, D., Mandel, T., and Kuhlemeier, C. (2000). Auxin regulates the initiation and radial position of plant lateral organs. Plant Cell 12 507-518.

Running, M. P., and Meyerowitz, E. M. (1996). Mutations in the PERIANTHIA gene of Arabidopsis specifically alter floral organ number and initiation pattern. Development 122, 1261-1269.

Schmid, M., Davison, T. S., Henz, S. R., Pape, U. J., Demar, M., Vingron, M., Schölkopf, B., Weigel, D., and Lohmann, J. U. (2005). A gene expression map of Arabidopsis thaliana development. Nat. Genet. 37, 501-506.

Schoof, H., Lenhard, M., Haecker, A. Mayer, K. F., Jürgens, G., and Laux, T. (2000). The stem cell population of Arabidopsis shoot meristems in maintained by a regulatory loop between the CLAVATA and WUSCHEL genes. Cell 100, 635-644.

To, J. P. C., Haberer, G., Ferreira, F. J., Deruère, J., Mason, M. G., Schaller, G. E., Alonso, J. M., Ecker, J. R., and Kieber, J. J. (2004). Type-A Arabidopsis response regulators are partially redundant negative regulators of cytokinin signaling. Plant Cel 16, 658-671.

Weigel, D., Alvarez, J., Smyth, D. R. Yanofsky, M. F., and Meyerowitz, E. M. (1992). LEAFY controls floral meristem identity in Arabidopsis. Cell 69, 843-859.

Weigel, D., and Glazebrook, J. (2002). Arabidopsis: A Laboratory Manual, 1st Edn. Cold Spring Harbor, NY: CSHL Press.

Werner, T., Motyka, V., Laucou, V., Smets, R., Van Onckelen, H., and Schmülling, T. (2003). Cytokinindeficient transgenic Arabidopsis plants show multiple developmental alterations indicating opposite functions of cytokinins in the regulation of shoot and root meristem activity. Plant Cell 15, 2532-2550.

Werner, T., and Schmülling, T. (2009). Cytokinin action in plant development. Curr. Opin. Plant Biol. 12, 527-538.
Wu, Z., Irizarry, R., Gentleman, R., Martinez-Murillo, F., and Spencer, F. (2004). A model-based background adjustment for oligonucleotide expression arrays. J. Am. Stat. Assoc. 99, 909-917.

Yanai, O., Shani, E., Dolezal, K., Tarkowski, P., Sablowski, R., Sandberg, G., Samach, A., and Ori, N. (2005). Arabidopsis KNOXI proteins activate cytokinin biosynthesis. Curr. Biol. 15, 1566-1571.

Zander, M., La Camera, S., Lamotte, O., Métraux, J.-P., and Gatz, C. (2010). Arabidopsis thaliana class-II TGA transcription factors are essential activators of jasmonic acid/ethyleneinduced defense responses. Plant J. 61, 200-210.

Zhao, Y., Christensen, S. K., Fankhauser, C., Cashman, J. R., Cohen, J. D. Weigel, D., and Chory, J. (2001). A role for flavin monooxygenaselike enzymes in auxin biosynthesis. Science 291, 306-309.

Zhao, Z., Andersen, S. U., Ljung, K., Dolezal, K., Miotk, A., Schultheiss, S. J., and Lohmann, J. U. (2010). Hormonal control of the shoot stem-cell niche. Nature 465, 1089-1092.

Conflict of Interest Statement: The authors declare that the research was conducted in the absence of any commercial or financial relationships that could be construed as a potential conflict of interest.

Received: 30 September 2011; paper pending published: 17 October 2011; accepted: 26 October 2011; published online: 21 November 2011.

Citation: Maier AT, Stehling-Sun S, Offenburger $S-L$ and Lohmann JU (2011) The bZIP transcription factor PERIANTHIA: a multifunctional hub for meristem control. Front. Plant Sci. 2:79. doi: 10.3389/fpls.2011.00079

This article was submitted to Frontiers in Plant Physiology, a specialty of Frontiers in Plant Science.

Copyright (c) 2011 Maier, Stehling-Sun, Offenburger and Lohmann. This is an open-access article subject to a nonexclusive license between the authors and Frontiers Media SA, which permits use, distribution and reproduction in other forums, provided the original authors and source are credited and other Frontiers conditions are complied with. 